\section{Tumor suppression and normal aging in mice with constitutively high p53 activity}

\author{
Susan M. Mendrysa, ${ }^{1,2,5,6}$ \\ Kathleen A. O'Leary, ${ }^{1,5,7}$ Matthew K. McElwee, ${ }^{1,8}$ \\ Jennifer Michalowski, ${ }^{1,9}$ Robert N. Eisenman, ${ }^{2}$ \\ Douglas A. Powell, ${ }^{3}$ and Mary Ellen Perry ${ }^{1,4,10}$
}

${ }^{1}$ Department of Oncology, University of Wisconsin, Madison, Wisconsin 53706, USA; ${ }^{2}$ Fred Hutchinson Cancer Research Center, Seattle, Washington 98109, USA; ${ }^{3}$ Data Management Services, National Cancer Institute,

Frederick, Maryland 21702, USA; ${ }^{4}$ Laboratory of Protein

Dynamics and Signaling, National Cancer Institute,

Frederick, Maryland 21702, USA

The p53 inhibitor murine double-minute gene 2 (Mdm2) is a target for potential cancer therapies, however increased p53 function can be lethal. To directly address whether reduced $M d m 2$ function can inhibit tumorigenesis without causing detrimental side effects, we exploited a hypomorphic murine allele of $m d m 2$ to compare the effects of decreased levels of $M d m 2$ and hence increased p53 activity on tumorigenesis and life span in mice. Here we report that mice with decreased levels of Mdm2 are resistant to tumor formation yet do not age prematurely, supporting the notion that $M d m 2$ is a promising target for cancer therapeutics.

Received September 23, 2005; revised version accepted November 2, 2005.

Activation of the p53 tumor suppressor is a current goal of many cancer therapeutic strategies (Lane and Fischer 2004; Vassilev et al. 2004; Yang et al. 2005). As a key proximal regulator of $\mathrm{p} 53$, murine double-minute gene 2 $(\mathrm{Mdm} 2)$ is a potential target for such chemotherapeutics, particularly in tumors in which p53 function is limited through mechanisms other than mutational inactivation. Mdm2 is a powerful inhibitor of p53, limiting p53 function by several mechanisms. It directly binds the transcriptional activation domain of p53 and blocks interactions with the basic transcription machinery (Momand et al. 1992; Thut et al. 1997). In addition, it promotes nuclear export of p53 and transfers ubiquitin to

[Keywords: Aging; tumor suppression; p53; Mdm2; apoptosis; cancer therapy]

${ }^{5}$ These authors contributed equally to this work.

Present addresses: ${ }^{6}$ Department of Basic Medical Sciences, Purdue University, West Lafayette, IN 47907, USA; ${ }^{7}$ Department of Comparative Biosciences, University of Wisconsin, Madison, WI 53706, USA; ${ }^{8}$ Integrated Toxicology Program, Duke University, Durham, NC 27708, USA; ${ }^{9}$ Howard Hughes Medical Institute, Chevy Chase, MD 20815, USA; ${ }^{10}$ Corresponding author.

E-MAIL perryma@mail.nih.gov; FAX (301) 402-1037.

Article and publication are at http://www.genesdev.org/cgi/doi/10.1101/ gad.1378506 p53, thereby enhancing its degradation (Honda et al. 1997; Roth et al. 1998). As little as a twofold decrease in $\mathrm{Mdm} 2$ expression increases basal p53 function in mice (Mendrysa et al. 2003), highlighting the exquisite sensitivity of p53 to Mdm2 levels. Conversely, a naturally occurring polymorphism in the human $m d m 2$ gene (SNP309) has been identified that allows increased $m d m 2$ expression and thereby decreased p53 function in people (Bond et al. 2004). SNP309 is strongly associated with a $10-y r$ acceleration of tumor onset, presumably due to decreased p53 tumor suppressor function. Small molecule inhibitors of $\mathrm{Mdm} 2$ have been developed that reduce tumor growth specifically by increasing the activity of p53 (Vassilev et al. 2004), thereby advancing the concept of $\mathrm{Mdm} 2$ as a chemopreventive or therapeutic target. Together, these studies suggest that modest inhibition of Mdm2 could potentially serve as an effective anticancer therapy.

The utility of this approach depends on whether therapeutic doses of $\mathrm{Mdm} 2$ inhibitors cause unacceptable side effects (Lane and Fischer 2004). Mdm2 is a critical survival factor as evidenced by the embryonic death of mice lacking Mdm2 (Jones et al. 1995; Montes de Oca Luna et al. 1995) and the lymphopenia of mice expressing $~ 30 \%$ of the wild-type level of Mdm2 (Mendrysa et al. 2003). To date, these as well as all other phenotypes associated with loss or decreased levels of Mdm2 have been demonstrated to be rescued by loss of p53, indicating that increased p53 activity is a direct consequence of decreased mdm2 expression. While activation of the tumor-suppressive function of p53 may be beneficial, there is controversial evidence that constitutively high p53 activity in nontumor cells accelerates aging in mice (Garcia-Cao et al. 2002; Tyner et al. 2002; Maier et al. 2004). If tumor-suppressive doses of p53 activity cause aging and/or lymphopenia, the utility of compounds that inhibit Mdm2 function and activate p53 may be limited.

Several studies have attempted to address the question of whether p53-mediated tumor suppression comes at the cost of accelerated aging, and they have provided conflicting results. Tyner et al. (2002) generated mice carrying a mutant $p 53$ gene $\left(p 53^{m}\right)$ that encodes a protein that can stimulate the activity of endogenous $\mathrm{p} 53$. In this strain, the incidence of tumorigenesis is reduced dramatically. However, $p 53^{\mathrm{m} / \mathrm{+}}$ mice die at younger ages than do wild-type mice, and prematurely exhibit several symptoms of aging including weight loss, lordokyphosis, thin skin, and osteoporosis, prompting the interpretation that high p53 activity causes tumor suppression at the cost of accelerated aging (Donehower 2002; Febeyre and Lowe 2002). However, despite their increased resistance to tumor formation, $p 53^{m /+}$ mice have not been demonstrated to have more p53 activity than wild-type mice. Moreover, it was recently reported that the generation of $p 53^{\mathrm{m} /+}$ mice led to the deletion of 24 genes, which is hypothesized to contribute to the aging phenotypes (Gentry and Venkatachalam 2005). Thus the etiology of the aging phenotypes in $p 53^{\mathrm{m} / \mathrm{+}}$ mice is not clear.

Additional studies have not clarified whether p53 promotes aging. "Super p53" mice carrying multiple transgenes of wild-type p53 age normally (Garcia-Cao et al. 2002). These mice have excessive levels of p53 activity following treatment with chemical carcinogens or radia- 
tion. However, basal levels of p53 activity are wild type (Garcia-Cao et al. 2002). Thus, these mice are not an appropriate system in which to test whether p53 activity accelerates aging. Indeed, the authors of this work suggested that constitutively high levels of p53 activity may be necessary to accelerate aging. More recently, Maier et al. (2004) found evidence of accelerated aging in transgenic mice carrying a truncated form of p53 that enhances some activities of endogenous wild-type p53. However, since these mice showed decreases in other p53 functions, the data could be interpreted as consistent with a role for p53 in preventing, rather than accelerating, aging. Indeed the model put forth by these authors suggests that insulin-like growth-factor signaling, which is inhibited by p53, promotes aging in these mice. Thus, it remains unclear whether increased p53 activity through $\mathrm{Mdm} 2$ inhibition would accelerate aging.

To directly test whether decreased Mdm2 activity and consequently high p53 activity suppresses tumor formation at the cost of accelerated aging, we took advantage of mice genetically engineered to express low levels of mdm2. Mdm2 $2^{\text {puro } / \Delta-12}$ mice, which have one hypomorphic and one null allele of $m d m 2$, express $\sim 30 \%$ of the wild-type level of $m d m 2$ and demonstrate an obvious increase in many functions of endogenous, wild-type p53 (Mendrysa et al. 2003). The mice are small, lymphopenic, and radiosensitive, all due to high p53 activity. All tissues of $m d m 2^{\text {puro/s7-12 }}$ mice have elevated levels of p53-dependent transcription and a subset undergoes spontaneous, p53-mediated apoptosis. All observed phenotypes of $m d m 2^{\text {puro/ } / 4-12}$ mice are completely rescued by deletion of p53 (Mendrysa et al. 2003). As endogenous p53 is constitutively active in $m d m 2^{\text {puro/ } / 4-12}$ mice, these mice are an ideal model for studying the physiological consequences of $\mathrm{Mdm} 2$ inhibition, and the resulting elevation in p53 function, on tumor suppression and aging.

\section{Results and Discussion}

\section{Mdm2 deficiency and p53 function}

Through the use of wild-type (+), hypomorphic (puro), and null $(\Delta 7-12)$ mdm2 alleles, we have generated mice with a range of $\mathrm{Mdm} 2$ levels $\left(\mathrm{mdm}^{+/+}>\right.$ $m d m 2^{+/ p u r o}>m d m 2^{+/ \Delta 7-12}>m d m 2^{\text {puro/ } / 4-12}$ ) (Mendrysa et al. 2003). In all mdm2 $2^{\text {puro/ } / 4-12}$ tissues tested, the level of $\mathrm{Mdm} 2$ is reduced to $\sim 30 \%$ of the level in wildtype mice, based on RNA and protein analyses (Fig. 1A; Mendrysa et al. 2003). Our initial characterization of $m d m 2^{\text {puro/ } / 4-12}$ mice demonstrated that the $\sim 70 \%$ decrease in $\mathrm{Mdm} 2$ results in the stimulation of p53 target gene expression in all tissues examined (Mendrysa et al. 2003). In addition, the basal apoptotic function of p53 is elevated in a subset of $m d m 2^{\text {puro/ } / 4-12}$ tissues (Mendrysa et al. 2003). For example, in the small intestines of mdm2 $2^{\text {puro/ } / 7-12}$ mice, spontaneous, p53-dependent apoptosis is increased 17-fold over that in wild-type mice (Fig. 1B; $p=0.010$ ). In contrast, the amount of p53dependent apoptosis is not increased in the colons of $m d m 2^{\text {puro } / \Delta 7^{7}-12}$ mice (Fig. $\left.1 \mathrm{~B} ; p=0.720\right) . M d m 2^{\text {puro } / \Delta 7-12}$ thymocytes also have an increase in p53-dependent apoptosis (two- to threefold) which occurs without a proportional increase in p53 protein levels (Mendrysa et al. 2003). Further characterization of p53 in $m d m 2^{\text {puro/ } / 4-12}$ mice demonstrates that the increased activity of p53 oc-

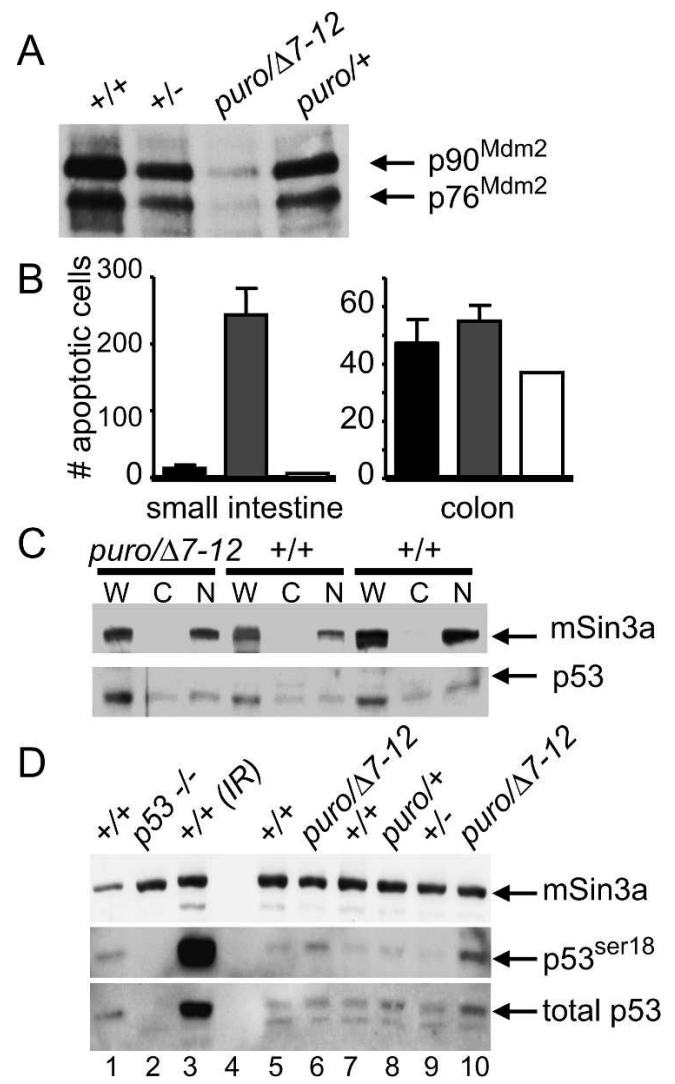

Figure 1. Decreased $\mathrm{Mdm} 2$ level and increased p53 activity in $m d m 2^{\text {puro/ } / 4-12}$ tissues. (A) Immunoprecipitation followed by Western analysis of Mdm2 protein in thymi from mice expressing four levels of Mdm2. (B, left graph) Spontaneous p53-dependent apoptosis in small intestines from wild-type (black bars), $m d m 2^{\text {puro/ } / \Delta-12}$ (gray bars) and mdm2 $2^{\text {puro/ } / \Delta-12} ; \mathrm{p} 53^{-/-}$(white bars) mice. The bars indicate the average number of TUNEL-positive cells per 100 crypts, with standard deviations indicated by error bars. (Right graph) Spontaneous p53-dependent apoptosis in colons from wild-type, $m d m 2^{\text {puro } / \Delta 7-12}$, and $m d m 2^{\text {puro } / \Delta 7-12 ;}{\mathrm{p} 53^{-/-}}$mice. The bars indicate the average number of TUNEL-positive cells per bundle of colon, with standard deviations indicated by error bars. $(C)$ Cellular fractionation of thymocytes. (W) Whole-cell lysate; (C) cytoplasmic fraction; $(\mathrm{N})$ nuclear fraction. The nuclear protein mSin3a is a control for the fractionation. $(D)$ Level of phosphorylated p53 in thymocytes. Lanes 1-3 show controls from wild-type mouse embryo fibroblasts, $\mathrm{p} 53^{-/}$MEFs, and irradiated wild-type MEFs, respectively; lane 4 is empty; and lanes 5-10 show whole-cell lysates of thymocytes from mice with four different levels of Mdm2. mSin3a is a loading control.

curs in the absence of enhanced nuclear localization (Fig. 1C) or an increase in the activating phosphorylation of Ser18 (Fig. 1D; Chao et al. 2003), further substantiating the notion that release of $\mathrm{Mdm} 2$ from the transactivation domain of p53 is sufficient to enhance p53 activity (Momand et al. 1992; Thut et al. 1997; Mendrysa et al. 2003).

\section{Tumor suppression by reduction of Mdm2 levels}

Given that the transactivation and apoptotic activities of p53 are increased in mice with subphysiological levels of Mdm2 (mdm2 $\left.2^{\text {puro/ } / 7-12}\right)$, we tested whether this increase in p53 function could suppress the formation of solid tumors. We specifically examined the incidence of tu- 
mors of the small intestine by generating $A p c^{\text {min/+ }}$ mice that express one of four levels of $\mathrm{Mdm} 2$. Apc $\mathrm{min}^{\mathrm{min}}$ mice were chosen because they have one mutant allele of the adenomatous polyposis coli $(A p c)$ tumor suppressor gene and are prone to spontaneous intestinal adenomas that rarely progress to carcinomas (Moser et al. 1990). Loss of p53 exacerbates the numbers of these benign tumors in $A p c^{m i n /+}$ mice (Halberg et al. 2000), suggesting that enhanced p53 would suppress tumor formation. As expected, decreased $\mathrm{Mdm} 2$ levels led to a reduction of benign tumors in $A p c^{\mathrm{min} /+}$ mice (Fig. 2A). At 5 mo of age, $A p c^{m i n /+}$ mice with wild-type amounts of $\mathrm{Mdm} 2$ $\left(A p c^{m i n /+} ; \mathrm{mdm}^{+/+}\right)$had an average of 48 intestinal adenomas whereas those expressing $\sim 80 \%$ of the wild-type level of $\mathrm{Mdm} 2\left(A p c^{\mathrm{min} /+} ; \mathrm{mdm}^{\text {puro/+ }}\right.$ mice $)$ had only 16 tumors per mouse (Fig. $2 \mathrm{~B} ; p=0.010$ ). Thus a subtle decrease in $\mathrm{Mdm} 2$ expression is sufficient to reduce tumor formation significantly. Mice with $\sim 30 \%$ of the wild-

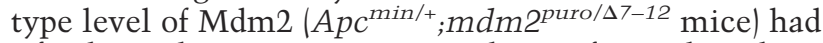
a further reduction in tumor number, to fewer than three tumors per mouse $(p<0.001)$, demonstrating that the threefold reduction of $\mathrm{Mdm} 2$ profoundly suppresses tumor formation.

\section{Does an increase in p53 activity cause aging?}

To determine whether constitutively high p53 activity resulting from decreased levels of Mdm2 leads to premature aging, we recorded the lifespans of a cohort of wildtype and $m d m 2^{\text {puro/s7-12 }}$ mice (Fig. 3). Between mice of the two genotypes, there was no difference in either the mean or maximal lifespans. The log rank test indicated no difference in the survival time distributions among the two groups of mice $(p=0.61)$. The mean survival for wild-type mice was $106 \mathrm{wk}$ whereas that for $m d m 2^{\text {puro/ }}$ $\Delta 7-12$ mice was 110 wk (106 and 104 wk, respectively, including mice sacrificed prior to morbidity). Seventyone percent of wild-type mice lived to be at least 24 mo of age, as did $73 \%$ of $m d m 2^{\text {puro/ } / 7-12}$ mice $158 \%$ and $54 \%$, respectively, including mice sacrificed prior to

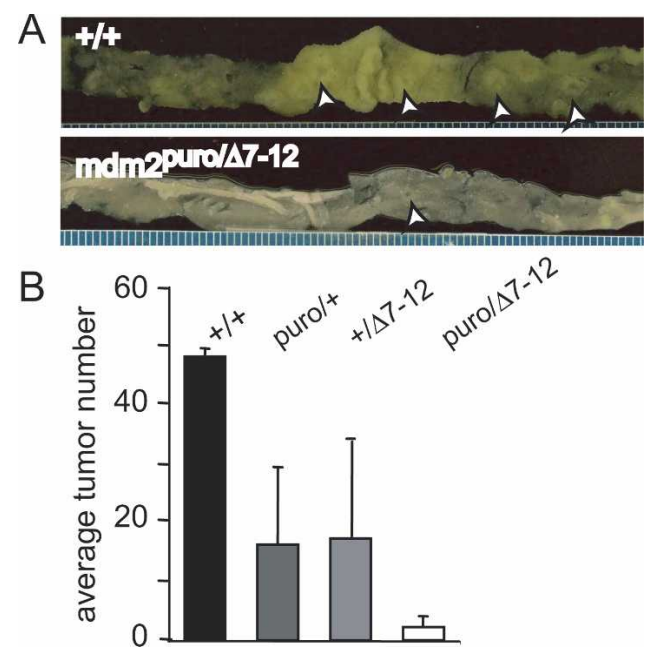

Figure 2. Tumor incidence in $A p c^{m i n /+}$ mice expressing different levels of Mdm2. (A) Representative portion of small intestines from wild-type and $m d m 2^{\text {puro } / \Delta 7-12}$ mice. The arrowheads indicate tumors. $(B)$ The number of adenomas along the length of the small intestines from $A p c^{\mathrm{min} /+}$ mice (average tumor number with standard deviations indicated by error bars).

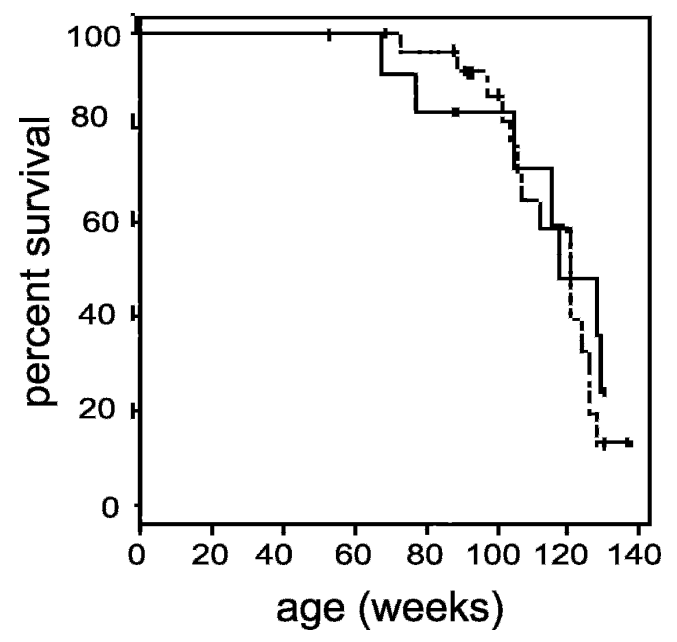

Figure 3. Kaplan-Meier survival curve of wild-type and mdm2 $2^{\text {puro } / \Delta 7-12}$ mice. The solid line indicates data from wildtype mice $(n=12)$, and the dashed line indicates data from mdm $2^{\text {puro } / \Delta 7-12}$ mice $(n=28)$. Hatch marks indicate mice sacrificed prior to morbidity.

morbidity). At the end of the study, four long-lived mice had to be sacrificed. They were two wild-type mice that were each 130 wk of age and two mdm2 $2^{\text {puro/ } / 7-12}$ mice that were 130 and 137 wk of age.

Fifty percent of aged wild-type mice developed spontaneous hepatomas, whereas only $17 \%$ of aged $m d m 2^{\text {puro/ } / 7-12}$ mice did so. This finding is of borderline statistical significance due to the small number of tumors in the aged cohort $(p=0.06)$. In contrast, a highly significant association between decreased Mdm2 and decreased tumorigenesis is evident when comparing the percentage of mice that developed tumors in more than one tissue. Fifty percent of aged wild-type mice had tumors in more than one tissue whereas only $8.3 \%$ of aged $m d m 2^{\text {puro/ } / 4-12}$ mice did $(p=0.014)$. Thus, an approximately threefold decrease in $\mathrm{Mdm} 2$ augments the tumor suppressive activity of p53 without causing a reduction in lifespan.

Next we investigated whether a reduction in $\mathrm{Mdm} 2$ elicited a number of aging-related phenotypes that have been ascribed to p53, including decreased body weight, reduced dermal thickness, reduced subcutaneous fat, and osteoporosis (Tyner et al. 2002; Maier et al. 2004). Since young $m d m 2^{\text {puro/ } / 7-12}$ mice are $15 \%-20 \%$ lighter than their wild-type counterparts (Mendrysa et al. 2003), we compared the rates of weight loss in aging mice of both genotypes. From 16 to 26 mo of age, male wild-type mice lost $24.1 \%$ of their body weight $(n=4)$, and male mdm2 $2^{\text {puro } / \Delta-12}$ mice lost $21.2 \%$ of their body weight $(n=4)$, indicating no change in weight loss due to excess p53 function $(p=0.84)$. Neither was there a significant difference in skin thickness in aged mice with different levels of Mdm2 (Fig. 4A). The mean dermal thickness was $0.208 \mathrm{~mm}( \pm 0.125)$ for six aged wild-type mice and $0.175 \mathrm{~mm}( \pm 0.076)$ for six aged $m d m 2^{\text {puro } / \Delta 7-12}$ mice. The small difference in dermal thickness was not statistically significant by either the $t$-test $(p=0.411)$ or the nonparametric Wilcoxon test $(p=0.500)$. Mean subcutaneous fat measured $0.0771 \mathrm{~mm}( \pm 0.109)$ in six wild-type mice and $0.0979 \mathrm{~mm}( \pm 0.216)$ in six $m d m 2^{\text {puro/ } / 4-12}$ mice. Again, there was no statistical difference in these 

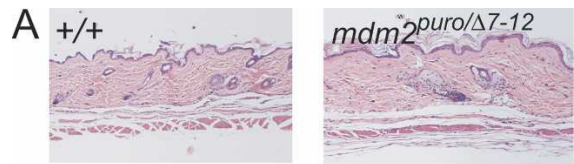

B

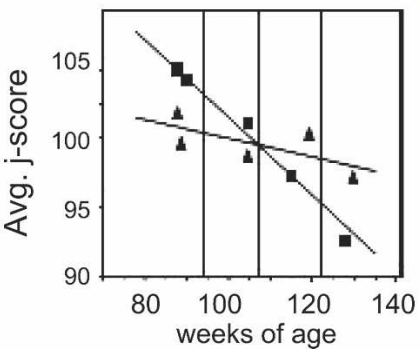

Figure 4. Skin and bone thickness in wild-type and $m d m 2^{\text {puro/ } / \Delta-12}$ mice. (A) Representative sections of dermis and epidermis from aged

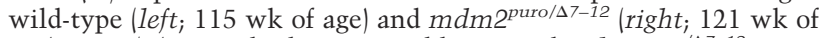
age) mice. $(B)$ Bone thickness in wild-type and $m d m 2^{\text {puro/ } / 4-12}$ mice. Each of five sex-matched pairs of aged wild-type (squares) and $m d m 2^{\text {puro/ } / 7-12}$ (triangles) mice were assigned a value (j-score) corresponding to the mean thickness of seven or more regions of bone and analyzed as described in the Materials and Methods. The regression model had a multiple R-squared of 0.934 and thus explains $93.4 \%$ of the variance in the bone thickness of the mice. The three vertical lines indicate the ages at which the two regression lines intersect (107 wk) and at which there were significant differences in bone thicknesses among the two genotypes (wild-type thicker at ages $<94$ wk and less thick at ages $>122$ wk).

values according to either the $t$-test $(p=0.771)$ or nonparametric Wilcoxon test $(p=1.00)$. Finally, the bone thickness of aged mdm $2^{\text {puro/ } / 4-12}$ mice was not reduced compared with that of aged wild-type mice (Fig. 4B). Whereas at ages $<94$ wk the bones of wild-type mice were significantly thicker than those of $m d m 2^{\text {puro/s7-12 }}$ mice, mdm2 $2^{\text {puro/ } / 4-12}$ mice had significantly thicker bones at ages $>122 \mathrm{wk}$. These changes in bone thickness are more consistent with a model in which p53 prevents rather than accelerates aging. No other aging phenotypes appear different in $m d m 2^{\text {puro/ }}$ 7-12 mice, indicating that any effect of the increased p53 function on aging in these mice must be quite subtle.

The lack of premature aging phenotypes in mice with reduced levels of $m d m 2$ indicates that increases in the function of p53 are not sufficient to cause aging. In both of the murine models used to associate p53 with accelerated aging, mutant p53 proteins lacking the $\mathrm{N}$ terminus were expressed along with wild-type protein (Tyner et al. 2002; Maier et al. 2004). N-terminally truncated forms of p53 can alter the preference of full-length p53 for specific promoters (Bourdon et al. 2005), suggesting that altered p53 function, not increased p53 function, may accelerate aging.

\section{Tumor suppression without adverse effects}

Our results clearly demonstrate that p53 activation achieved through $\mathrm{Mdm} 2$ inhibition significantly suppresses tumor formation without the negative consequences of accelerated aging. Although aging in mdm $2^{\text {puro/ } / 4-12}$ mice was unaffected, previous analyses indicated that lymphopenia and intestinal apoptosis were increased (Mendrysa et al. 2003) and are two potentially detrimental side-effects of elevated p53 function. Given that even $m d m 2^{+/ p u r o}$ mice, which express $\sim 80 \%$ of the level of wild-type Mdm2, were significantly pro- tected against tumor formation, we next determined whether all three tumor-suppressive doses of p53 achieved through Mdm2 inhibition cause lymphopenia and enhanced intestinal apoptosis. We enumerated the number of apoptotic cells in the crypts of the small intestines of 5 -wk-old mice expressing $100 \%, 80 \%, 50 \%$, or $30 \%$ of the wild-type level of Mdm2. Consistent with previous results (Mendrysa et al. 2003), mdm2 $2^{\text {puro/s7-12 }}$ mice had an $\sim 15$-fold $(p<0.001)$ increase over the wildtype number of apoptotic cells in the crypts of the small intestine. In contrast, mice with $50 \%$ of the level of Mdm2 ( $m d m 2^{+/ \Delta 7-12}$ mice) had only a fourfold increase $(p=0.002)$ and mice with $80 \%$ of the wild-type level of Mdm2 had no increase in apoptotic cells $(p=0.07)$. Thus a tumor-suppressive dose of $\sim 80 \%$ of the wild-type level of $\mathrm{Mdm} 2$ is sufficient to maintain intestinal integrity.

We next counted both white blood cells (WBCs) (Fig. 5) and lymphocytes (PBLs) from peripheral blood of 5-wkold mice expressing four levels of $\mathrm{Mdm} 2$. Whereas $m d m 2^{\text {puro/ } / 4-12}$ mice showed the expected deficiency in WBCs $(p=0.004)$, neither $m d m 2^{\text {puro/+ }}$ nor $m d m 2^{+/ \Delta 7-12}$ mice were deficient in these cell types $(p=0.352$ and $p=0.171$, respectively). Likewise, $m d m 2^{\text {puro } / \Delta 7-12}$ mice showed a profound decrease in PBLs $(p=0.004)$, but neither $m d m 2^{\text {puro/+ }}$ nor $m d m 2^{+/ \Delta 7-12}$ mice were deficient ( $p=1.00$ and $p=0.067$, respectively). Thus Mdm2 activity can be reduced $\sim 20 \%-50 \%$ to prevent tumor formation without causing lymphopenia. Because blood sampling is noninvasive, these results suggest that people taking $\mathrm{Mdm} 2$ inhibitors could be readily monitored for signs of lymphopenia. If necessary, their doses could be adjusted to prevent any adverse effects. However, as one note of caution for therapeutic applications of $\mathrm{Mdm} 2$ inhibitors, it has been observed that $M d m 2^{\text {puro/+ }}$ mice are slightly radiosensitive and $m d m 2^{\text {puro/s7-12 }}$ mice are very radiosensitive (Mendrysa et al. 2003). These findings suggest that careful dosing of $\mathrm{Mdm} 2$ inhibitors will be required if combined with radiotherapy.

In addition to many possible uses as a therapeutic target, $\mathrm{Mdm} 2$ has great promise as a chemopreventive target. The fact that $m d m 2^{\text {puro/ } / 7-12}$ mice live as long as do wild-type mice demonstrates that $\mathrm{Mdm} 2$ inhibitors could be titrated such that they could be tolerated for prolonged periods. The profound decrease in adenomas in $A p c^{m i n /+} ; m d m 2^{\text {puro/ } / 4-12}$ mice suggests that inhibitors of $\mathrm{Mdm} 2$ may be effective in preventing adenomas in families with inherited mutations in the apc gene (familial adenomatous polyposis cohorts) (Strate and Syngal 2005). In addition, people who are homozygous for SNP309 in the mdm2 promoter ( 11\% of the population)

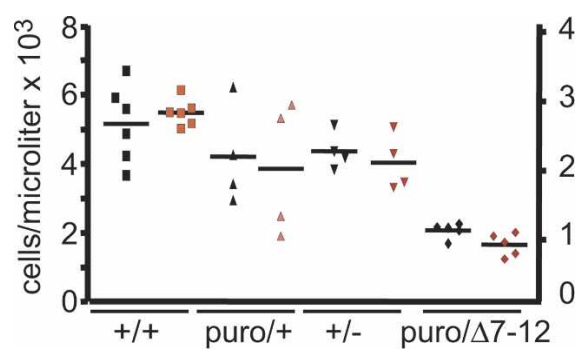

Figure 5. Peripheral blood counts of mice expressing different levels of Mdm2. White blood cells (black, left scale) and peripheral blood lymphocytes (orange, right scale) are shown. The genotypes of the mice are indicated. The horizontal bar represents the mean. 
are likely to benefit from Mdm2 inhibition (Bond et al. 2004). Careful titration of Mdm2 inhibitors could theoretically restore their p53 function to wild-type levels and delay or prevent tumorigenesis.

Together, these results demonstrate that constitutively increased p53 activity does not cause accelerated aging and confirm $\mathrm{Mdm} 2$ as a promising target for chemoprevention and for cancer therapy.

\section{Materials and methods}

Mice

Characterization of $m d m 2^{\text {puro/s7-12 }}$ mice has been described previously (Mendrysa et al. 2003). All mdm2 $2^{\text {puro/ } / 4-12}$ mice were either C57Bl/ $6 \times 129$ EvSv F1 hybrids or on mixed 129/B6 backgrounds. During the survival study, several mice were sacrificed prior to the onset of morbidity. These include three mice of each genotype that were sacrificed at $88-89$ wk of age to ensure matched samples of skin and bone; one mouse died during an eye bleed; four mice with skin lesions were sacrificed on the order of the veterinarian; and two mice of each genotype (130-137 wk of age) were sacrificed at the end of the protocol. Necropsies were performed on all mice and histological identification of tumors was performed on all tissues that had not undergone autolysis. For the intestinal tumor analysis, $A p c^{\mathrm{min} /+}$ mice (Moser et al. 1990) on a C57Bl/6 background were used to generate $A p c^{+/+}$and $A p c^{\mathrm{min} /+} \mathrm{C} 57 \mathrm{Bl} / 6 \times 129 \mathrm{EvSv}$ F1 hybrids of four $m d m 2$ genotypes. Animal experiments were carried out in AALAC approved facilities under protocols approved by the Animal Care and Use Committees of the University of Wisconsin (most studies) or the Fred Hutchinson Cancer Research Center ( $A p c^{\text {min }}$ tumor study).

Protein analysis

Immunoprecipitation/Western blot analysis of $\mathrm{Mdm} 2$ protein was performed as described previously (Mendrysa et al. 2003). For analysis of p53 subcellular localization, nuclear and cytoplasmic extracts were made using a previously described procedure with slight modification (Cheshire and Baldwin 1997). P53 was detected using AB7 (Oncogene Research Products). Purity of nuclear and cytoplasmic fractions was evaluated using $\mathrm{mSin} 3 \mathrm{a}$ as a nuclear marker (Santa Cruz, clone 994).

Phospho-p53 $3^{\text {Ser18 }}$ (human Ser15) was analyzed in whole-cell lysates from isolated thymocytes prepared essentially as described in Mendrysa et al. (2003). Thirty-five micrograms of lysate were loaded in each lane. Blots were first detected with Phospho-p53 ${ }^{\text {Ser15 }}$ (Cell Signaling, catalog no. \#9284) then stripped and redetected with pan-p53 antibody CM5 (Novocastra).

\section{Skin thickness}

Dorsal skin samples were taken from six age- and sex-matched pairs of wild-type and $m d m 2^{\text {puro/ } / 7-12}$ mice aged from 88 to $129 \mathrm{wk}$ of age. Samples were immersion-fixed in $10 \%$ neutral buffered formalin (NBF) and processed for paraffin embedding. Histological examination was done on $5-\mu \mathrm{m}$ sections stained with hematoxylin and eosin. Dermal thickness and subcutaneous fat were measured using a $20 \times$ microscope objective and a $10 \times$ ocular eye piece with inserted grid. Multiple measurements were taken to determine a range.

\section{Bone thickness}

Bone samples were taken from five age- and sex-matched pairs of wildtype and $m d m 2^{\text {puro/ } / \Delta-12}$ mice aged from 88 to 129 wk of age. Following immersion-fixation in $10 \% \mathrm{NBF}$, bone was decalcified for $48 \mathrm{~h}$. Histological examination was done on 5 - $\mu \mathrm{m}$ sections stained with hematoxylin and eosin. Cortical bone thickness (bone marrow space to the external bone surface) was measured for the head, neck, mid-shaft and distal-shaft of the femur and tibia; mid-vertebral body of two mid-thoracic vertebrae; and mid-body of three sternebrae (distal or posterior body closest to the xiphoid process, a middle and a more proximal body) using a $20 \times$ microscope objective and a 10× ocular eye piece with inserted grid.

\section{TUNEL}

To assess apoptosis, 5 - $\mu \mathrm{m}$ sections of the small intestines from mice were stained with the ApopTag-terminal deoxynucleotidyl transferase nick end labeling (TUNEL) kit from Chemicon.
Tumorigenesis

$A p c^{\min /+}$ mice of each of four $m d m 2$ genotypes were sacrificed by $\mathrm{CO}_{2}$ asphyxiation at 5 mo of age. The entire intestinal tract was removed and fixed in $10 \%$ NBF followed by storage in $70 \%$ ethanol. Tumors along the length of the small intestine were scored blindly under a dissecting microscope.

Peripheral blood analysis

Peripheral blood was collected and analyzed as described in Mendrysa et al. (2003).

\section{Statistics}

Spontaneous tumor incidence across different genotypes was analyzed via the Fisher Exact Test. Tumor data on $A p c^{m i n}$ mice was analyzed by means of the Welch modified ANOVA procedure and the Games-Howell multiple comparisons procedure. Both of these techniques were used because they permit group comparisons when group variances are significantly different, as they were in this case (Kirk 1982). Additionally, the nonparametric Kruskal-Wallis test, with follow-up pairwise MannWhitney Wilcoxon tests was employed. These tests make neither distributional nor homoskedasticity (equality of variance) assumptions.

To determine whether the concentration of peripheral blood lymphocytes or white blood cells differed among mice with different amounts of Mdm2, pairwise Mann-Whitney Wilcoxon tests were run, comparing the mean ranks for each of the other three genotypes with the mean rank for wild-type mice.

The analysis of bone thickness data was done by means of the analysis of covariance (ANCOVA) technique with genotype as the grouping variable, age as the covariate, and a composite measure of bone thickness as the dependent variable (see below). Since the ANCOVA, done via a multiple regression approach, indicated that the best fitting regression lines (age regressed on bone thickness) for the two genotypes had significantly different slopes, the modified Johnson-Neyman (Potoff et al. 1964) technique was employed. This technique permits the determination of regions along the covariate (age) axis where the two genotypes have significantly different regression lines and also the regions where they do not have significantly different regression lines.

The composite measure of bone thickness was motivated by the fact that each of the mice had potentially thirteen different bone thickness measurements but five (one-half) of the mice had one or more missing measurements. Five had complete data, two had one missing measurement, two had three missing measurements, and one had six missing measurements. Since each measure was of a different bone, a measure had to be developed to summarize the bone thickness for a mouse. For each mouse the z-transform was computed for each measure for which there was data for the mouse. The $\mathrm{z}$-transform is equal to the mouse's score on the measure minus the mean (across mice) on the measure, with this difference divided by the standard deviation (across mice) on this measure. The $z$-transform has a mean of zero and a standard deviation of one. The $\mathrm{z}$-transforms were in turn rescaled to a " $\mathrm{j}$ " transform, having a mean of 100 and a standard deviation of 10 . Therefore, for each mouse there are varying numbers of $j$-transforms depending on the number of bone measurements reported for the mouse. The composite measure that served as a common measure of bone thickness for each mouse was the mean of its available $j$-transforms. Thus each mouse had a single index, reflecting its relative standing with respect to bone thickness.

\section{Acknowledgments}

We are grateful to the Pathology/Histotechnology Laboratory, NCI-Frederick for histological services, and to Dr. C. Dahlem Smith of the Laboratory Animal Science Program, NCI-Frederick, for measuring skin and bone thickness. We thank Drs. A.P. Gendron-Fitzpatrick and Ruth Sullivan of the University of Wisconsin Veterinary School for performing necropsies on aged mice. We thank Dr. Stephen Jones, University of Massachusetts, for $m d m 2^{+/ \Delta 7-12}$ mice, and Dr. Christopher Kemp, Fred Hutchinson Cancer Research Center, for $\mathrm{Apc}^{\mathrm{min} /+}$ mice. The critical comments of Dr. Allan Weissman are appreciated. This research was supported in part by the Intramural Research Program of the NIH, National Cancer Institute, Center for Cancer Research, and NIH grants to the McArdle Laboratory for Cancer Research, M.E.P., and R.N.E. S.M.M was supported by a postdoctoral fellowship from the American Cancer Society. 


\section{References}

Bond, G.L., Wenwei, H., Bond, E.E., Robins, H., Lutzker, S.G., Arva, N.C. Bargonetti, J., Bartel, F., Taubert, H., Wuerl, P., et al. 2004. A single nucleotide polymorphism in the MDM2 promoter attenuates the p53 tumor suppressor pathway and accelerates tumor formation in humans. Cell 119: 591-602.

Bourdon, J.-C., Fernandes, K., Murray-Zmijewski, F., Liu, G., Diot, A., Xirodimas, D.P., Saville, M.K., and Lane D.P. 2005. p53 isoforms can regulate p53 transcriptional activity. Genes \& Dev. 19: 2122-2137.

Chao, C., Hergenhahn, M., Kaeser, M.D., Wu, Z., Saito, S., Iggo, R., Hollstein, M., Appella, E., and Xu, Y. 2003. Cell type- and promoterspecific roles of ser18 phosphorylation in regulating p53. J. Biol. Chem. 278: 41028-41033.

Cheshire, J.L. and Baldwin, A.S. 1997. Synergistic activation of NF-кB by tumor necrosis factor $\alpha$ and $\gamma$ interferon via enhanced degradation and de novo ІкВ $\beta$ degradation. Mol. Cell. Biol. 17: 6746-6754.

Donehower, L.A. 2002. Does p53 affect organismal aging? J. Cell. Phys. 192: 23-30.

Febeyre, G. and Lowe, S.W. 2002. The price of tumor suppression? Nature 415: 26-27.

Garcia-Cao, I., Garcia-Cao, M., Martin-Caballero, J., Criado, L.M., Klatt, P., Flores, J.M., Weill, J.-C., Blasco, M.A., and Serrano, M. 2002. 'Super p53' mice exhibit enhanced DNA damage response, are tumor resistant and age normally. EMBO J. 21: 6225-6235.

Gentry, A. and Venkatachalam, S. 2005. Complicating the role of p53 in aging. Aging Cell 4: 157-160.

Halberg, R.B., Katzung, D.S., Hoff, P.D., Moser, A.R., Cole, C.E., Lubet, R.A., Donehower, L.A., Jacoby, R.F., and Dove, W.F. 2000. Tumorigenesis in the multiple intestinal neoplasia mouse: Redundancy of negative regulators and specificity of modifiers. Proc. Nat1. Acad. Sci. 97: 3461-3466

Honda, R., Tanaka, H., and Yasuda, H. 1997. Oncoprotein MDM2 is a ubiquitin ligase for tumor suppressor p53. FEBS Lett. 420: 25-27.

Jones, S.J., Roe, A.E., Donehower, L.A., and Bradley, A. 1995. Rescue of embryonic lethality in MDM2-deficient mice by absence of p53. $\mathrm{Na}$ ture 378: 206-208.

Kirk, R.E. 1982. Experimental design: Procedures for the behavioral sciences, 2nd ed., pp. 106-127. Brooks/Cole, Monterey, CA

Lane, D.P. and Fischer, P.M. 2004. Turning the key on p53. Nature 427: 789-790.

Maier, B., Gluba, W., Bernier, B., Turner, T., Mohammad, K., Guise, T., Sutherland, A., Thorner, M., and Scrable, H. 2004. Modulation of mammalian life span by the short isoform of p53. Genes \& Dev. 18: 306-319.

Mendrysa, S.M., McElwee, M.K., Michalowski, J., O'Leary, K.A., Young K.M., and Perry, M.E. 2003. Mdm2 is critical for inhibition of p53 during lymphopoiesis and the response to ionizing radiation. Mol. Cell. Biol. 23: 462-473.

Momand, J., Zambetti, G.P., Olson, D.C., George, D., and Levine, A.J. 1992. The $m d m-2$ oncogene product forms a complex with the p53 protein and inhibits p53-mediated transcription. Cell 69: 1237-1245.

Montes de Oca Luna, R., Wagner, D.S., and Lozano, G. 1995. Rescue of early embryonic lethality in mdm2-deficient mice by deletion of p53. Nature 378: 203-206.

Moser, A.R., Pitot, H.C., and Dove, W.F. 1990. A dominant mutation that predisposes to multiple intestinal neoplasia in the mouse. Science 247: 322-324.

Potoff, R.F. 1964. On the Johnson-Neyman technique and extensions thereof. Psycometrika 29: 241-256.

Roth, J.M., Dobbelstein, M., Freedman, D.A., Shenk, T., and Levine, A.J. 1998. Nucleo-cytoplasmic shuttling of the hdm2 oncoprotein regulates the level of p53 via a pathway used by the human immunodeficiency virus rev protein. EMBO J. 17: 554-564.

Strate, L.L. and Syngal, S. 2005. Hereditary colorectal cancer syndromes. Cancer Causes Control 16: 201-213.

Thut, C.J., Goodrich, J.A., and Tjian, R. 1997. Repression of p53-mediated transcription by MDM2: A dual mechanism. Genes \& Dev. 11: 1974 1986

Tyner, S.D., Venkatachalam, S., Choi, J., Jones, S., Ghebranious, N., Igelmann, H., Lu, X., Soron, G., Cooper, B., Brayton, C., et al. 2002. P53 mutant mice that display early ageing-associated phenotypes. Nature 415: $45-53$
Vassilev, L.T., Vu, B.T., Graves, B., Carvajal, D., Podlaski, F., Filipovic, Z., Kong, N., Kammlott, U., Lukacs, C., Klein, C., et al. 2004. In vivo activation of the p53 pathway by small-molecule antagonists of MDM2. Science 303: 844-848.

Yang, Y., Ludwig, R.L., Jensen, J.P., Pierre, S.A., Medaglia, M.V., Davydov, I.V., Safiran, Y.J., Oberoi, P., Kenten, J.H., Phillips, A.C., et al. 2005. Small molecular inhibitors of HDM2 ubiquitin ligase activity stabilize and activate p53 in cells. Cancer Cell 7: 547-559. 


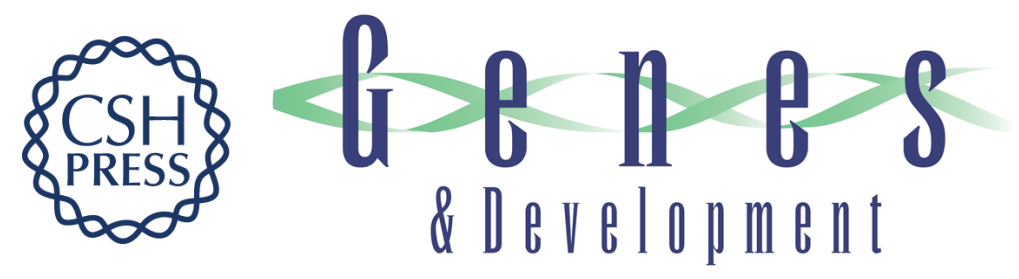

\section{Tumor suppression and normal aging in mice with constitutively high p53 activity}

Susan M. Mendrysa, Kathleen A. O'Leary, Matthew K. McElwee, et al.

Genes Dev. 2006, 20:

Access the most recent version at doi:10.1101/gad.1378506
Related Content Unleashing the power of p53: lessons from mice and men
Masha V. Poyurovsky and Carol Prives
Genes Dev. January , 2006 20: 125-131
References This article cites 24 articles, 11 of which can be accessed free at: http://genesdev.cshlp.org/content/20/1/16.full.html\#ref-list-1
Articles cited in:
http://genesdev.cshlp.org/content/20/1/16.full.html\#related-urls
License
Email Alerting Receive free email alerts when new articles cite this article - sign up in the box at the top Service right corner of the article or click here.

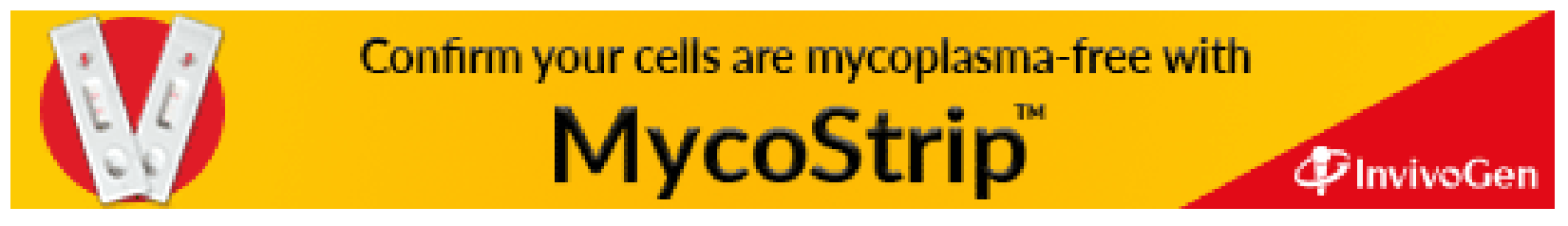

